\title{
Impact of smoking on gingival inflammation in representative samples of three South American cities
}

\author{
Cassiano Kuchenbecker \\ RÖSING(a) \\ Sabrina Carvalho GOMES(a) \\ Paola CARVAJAL (b) iD \\ Mariel GÓMEZ(c) iD \\ Ricardo COSTA(a) \\ Andres TOLEDO(c) iD \\ Fernando SOLANES(b) iD \\ Hugo ROMANELLI(c) iD \\ Jorge GAMONAL (b) iD \\ Rui Vicente OPPERMANN(a)

\footnotetext{
(a)Federal University of Rio Grande do Sul - UFRGS, Department of Conservative Dentistry, Faculty of Dentistry, Porto Alegre, RS, Brazil.
} \\ (b) University of Chile, Faculty of Dentistry, \\ Laboratory of Periodontal Biology, \\ Santiago, Chile. \\ (c)Maimónides University, School of Dentistry, \\ Career of Specialist in Periodontics, Buenos \\ Aires, Argentine.
}

Declaration of Interests: The authors certify that they have no commercial or associative interest that represents a conflict of interest in connection with the manuscript.

Corresponding Author: Cassiano Kuchenbecker Rösing E-mail: ckrosing@hotmail.com

https://doi.org/10.1590/1807-3107bor-2019.vol33.0090

Submitted: May 22, 2018

Accepted for publication: May 2, 2019

Last revision: July 22, 2019

\begin{abstract}
The aim of this study was to investigate the impact of smoking on gingival inflammation in a representative sample of 1,650 adults from Santiago (Chile), Porto Alegre (Brazil), and Tucumán (Argentina). A questionnaire was administered to participants to gather demographic and behavioral characteristics, including smoking habits. The participants were clinically examined to obtain gingival index (GI), gingival bleeding index (GBI), visible plaque index (VPI), and calculus presence values. Gingival inflammation was defined as a mean GI $>0.5$. Heavy smokers presented significantly lower levels of gingival inflammation, as reflected by both GI and GBI, than both light and moderate smokers, despite their having increased amounts of plaque and calculus. Being 50 years old or older [odds ratio (OR), 1.93], a VPI $\geq 30 \%$ (OR, 28.1), and self-reported diabetes (OR, 2.79) were positively associated with detection of gingival inflammation. In conclusion, the occurrence of clinically detectable gingival inflammation was lower in heavy smokers than light and moderate smokers. Older age, diabetes, and visible plaque emerged as risk indicators of gingivitis. Plaque and gingival indices are significantly associated regardless of the smoking status.
\end{abstract}

Keywords: Epidemiology; Smoking; Gingivitis.

\section{Introduction}

There are limited epidemiological data regarding the occurrence of gingival inflammation in adults worldwide. The majority of studies examining the prevalence and distribution of gingival inflammation have been performed in young children and adolescents. ${ }^{1}$ Gingival inflammation epidemiology reviews have demonstrated that much of the information for periodontal disease has been obtained with systems not designed to assess the prevalence of gingivitis, such as the community periodontal index. ${ }^{2}$ Anecdotal reporting has suggested that gingival inflammation may be a ubiquitous condition, affecting essentially all children regardless of geographical region. ${ }^{3}$

Interest in determined the prevalence and associated factors of gingival inflammation is based on its being a precursor of periodontitis, which can have negative health consequences, including systemic conditions, that affect quality of life. ${ }^{4}$ Knowing gum disease-associated factors will 
support the design of better primary and secondary preventative programs and the establishment of more effective therapeutic approaches.

Smoking, which is highly prevalent worldwide, has been associated with periodontal diseases as well as various other potentially lethal diseases, including cancer, stroke, and heart disease. ${ }^{5,6}$ Thus, smoking has a strong impact on healthcare costs and mortality., ${ }^{7,9}$ With respect to oral health specifically, smoking has been associated with the progression of periodontal disease ${ }^{10,11}$ and severe periodontal attachment loss. ${ }^{12,13}$ However, there is little information regarding the impact of smoking on gingival inflammation. Muller et al. ${ }^{14}$ reported that bleeding on probing was reduced in a small clinical cohort of young-adult smokers, irrespective of the distribution of plaque and calculus. In a follow-up longitudinal analysis of the same cohort, Muller et al. ${ }^{15}$ found that plaque and gingival inflammation did not correlate as directly as expected when smoking was considered. Contrarily, the same group reported in a later study that smoking was not associated with less bleeding. ${ }^{16}$ These published studies were not performed with an assessment tool specifically designed for examining marginal gingival inflammation and did not enroll large representative samples. Thus, the impact of smoking on gum disease remains to be clarified, especially in relation to the notion that smoking may mask signs of gingival inflammation. A lack of scientific understanding in this regard could lead to misleading diagnostic approaches.

The aim of the present study was to examine whether smoking affects detection of gingival inflammation in a representative sample recruited from three South American cities. We hypothesized that smoking would be found to mask clinical signs of gingival inflammation.

\section{Methodology}

\section{Study design and outcomes}

The present study was an analytical, multi-center population-based cross-sectional epidemiological study conducted between January and July of 2014. The main outcome analyzed was gingival inflammation, according to a previously described ${ }^{17}$ gingival index (GI). Secondary outcomes assessed included presence/absence of gingival bleeding index (GBI), visible plaque index $(\mathrm{VPI})^{18}$, and calculus.

\section{Sample size and participants}

To obtain a representative study population, participants were selected according to the sampling strategy, inclusion criteria, and exclusion criteria described by Carvajal and colleagues. ${ }^{19}$ The study population was comprised of adults from the cities of Santiago (Chile), Porto Alegre (Brazil), and Tucumán (Argentina). Sample size was calculated based on an estimated gingival inflammation prevalence of 93.9\% and a previously published average gingival index $>0.5^{20}$. To obtain a 95\% confidence interval with a $2 \%$ error range, it was estimated that we should enroll 550 individuals from each city. Thus, a total of 1650 participants were enrolled (550 per city).

\section{Ethical considerations}

The study protocol employed was in accordance with the Declaration of Helsinki and was reviewed and approved by the Institutional Review Boards of the University of Chile, Federal University of Rio Grande do Sul, and University of Maimonides. Before being interviewed and undergoing a clinical examination, each participant was informed about aims of the study and signed an informed consent form.

\section{Interview}

A structured interview questionnaire was prepared and tested for understanding in each of the three study sites, and then adapted as necessary for each sites. The questionnaire was comprised of open and closed questions about socio-demographic variables, oral hygiene habits, general health, attitudes and knowledge related to oral health, access to dental services, and behavioral factors. Demographic information collected included age, sex, civil status, educational level (did not complete high school, completed high school, some college, university degree, or postgraduate degree). General health information included self-reported diseases, including diabetes. For the behavioral factor of current smoking status, participants were asked if they smoked, and if so if they smoked $<5,5-10$, or $>10$ cigarettes per day. Life 
exposure to smoking was calculated in pack-years and classified as described below. ${ }^{19}$

\section{Clinical examination}

Prior to the initiation of the study, the principal investigators, reference examiner (CKR), and study examiners (RC, AT and FS) completed an extensive review of the study protocol to standardize the application of diagnostic criteria. Duplicate examinations were performed by each examiner in at least 10 patients, similar to those under study, prior to this study. Intra- and inter-examiner kappa coefficients for $\mathrm{GBl}, \mathrm{VPl}$, and Calculus index were $>0.7$ for all examiners.

The GI employed was Löe and Silness GI with the Löe modification. ${ }^{17}$ Mean GI values were calculated to evaluate the gingival health of each participant. Absence (0) or presence (1) of VPl was scored for six sites per tooth. ${ }^{18}$ Absence (0) or presence (1) of calculus was scored in lower anterior teeth on three lingual surfaces: disto-lingual, mid-lingual, and mesio-lingual.

\section{Data analysis}

Analyses of the data were performed with Stata/IC 13.1 for Mac. Categorical variables are expressed in absolute frequency and percentage. Continuous variables are presented as means with standard deviations (SDs) or frequency distribution of sub-categories.

Based on smoking exposure (calculated pack-years), the study participants were categorized as non-smokers, light smokers ( $<90$ pack-years), moderate smokers (90-182 pack-years), or heavy smokers (>182 pack-years). Gingival inflammation severity was categorized as follows: light, mean $\mathrm{GI}=0.5-1.0$; moderate, mean GI = 1.1-2.0; and severe, mean GI >2.0). Mean GI values were calculated for all sites and for interproximal sites. VPl was dichotomized into plaque observed at $<30 \%$ or $\geq 30 \%$ of examined sites. The Calculus Index was calculated as the $\%$ of observed sites with calculus. The GBl index ${ }^{18}$ reflects the $\%$ of observed sites with scores of 2 or 3 .

The continuous variables did not have normal distribution, according to the Shapiro-Wilk test, and were therefore analyzed with Kruskal-Wallis tests.
Nominal variables were analyzed with chi-squared tests when there was a sufficient sample size or relatively even distribution; otherwise, Fisher's exact tests were used.

A multi-variable logistic regression model was built to assess the contribution of each variable (age, gender, diabetes, smoking, plaque, calculus, oral hygiene habit, and educational level) on the primary outcome (i.e. the occurrence of severe periodonal inflammation). Variables with univariable analyses associations with a significance level of $p \leq 0.25$ were included in the model if they altered the coefficient by at least $10 \%$. Odds ratios (ORs) were calculated with $95 \%$ confidence intervals (CIs).

VPl values were correlated with GI values with Spearman's correlational analyses; coefficients were obtained for non-smokers and each smoker category, because the data were not non-normally distributed according to the Shapiro Wilk test,. Statistical significance was defined as $p<0.05$.

\section{Results}

The socio-demographic and clinical characteristics of the sample $(n=1650)$ are summarized in Table 1. The majority of participants were female $(52.6 \%)$ and the largest age-band group was the $\geq 50$ years group (33\%). The majority of patients had completed high school, without a university degree; and the vast majority of patients were not diabetic.

Clinical outcomes in relation to smoking exposure groups are reported in Table 2. Regarding smoking exposure, $28.8 \%$ were smokers of any intensity and $13.5 \%$ were heavy smokers. Mean GI values for all tooth surfaces were similar to the values obtained for proximal sites only. Light smokers and moderate smokers had significantly higher GI values than nonsmokers. Meanwhile, the GI value obtained for the heavy smoker group was statistically similar to that of the non-smoker group. Among the smoking groups, only the light smokers were significantly more likely than non-smokers to have a GBl elevated to $\geq 50 \%$, whereas the heavy smokers were significantly less likely to do so. Each of the three smoking groups had significantly higher mean VPI values than that of the non-smoker group. Calculus was found significantly 
- Impact of smoking on gingival inflammation in representative samples of three South American cities

Table 1. Sociodemographic and clinical characteristics of the study sample.

\begin{tabular}{|c|c|c|c|c|c|c|c|c|c|c|}
\hline \multirow{3}{*}{ Variable } & \multirow{2}{*}{\multicolumn{2}{|c|}{$\begin{array}{c}\text { Non-smoker } \\
n=1180\end{array}$}} & \multirow{2}{*}{\multicolumn{2}{|c|}{$\begin{array}{l}\text { Light smoker } \\
\qquad n=171\end{array}$}} & \multirow{2}{*}{\multicolumn{2}{|c|}{$\begin{array}{c}\text { Moderate smoker } \\
\qquad n=76\end{array}$}} & \multirow{2}{*}{\multicolumn{2}{|c|}{$\begin{array}{c}\text { Heavy smoker } \\
n=223\end{array}$}} & \multirow{2}{*}{\multicolumn{2}{|c|}{$\begin{array}{c}\text { Total } \\
\mathrm{n}=1650\end{array}$}} \\
\hline & & & & & & & & & & \\
\hline & $n$ & $\%$ & $\mathrm{~N}$ & $\%$ & $n$ & $\%$ & $n$ & $\%$ & $n$ & $\%$ \\
\hline \multicolumn{11}{|l|}{ Gender } \\
\hline Males & 542 & 69.2 & 72 & 9.2 & 35 & 4.5 & 134 & 17.1 & 783 & 47.4 \\
\hline Females & 638 & 73.6 & 99 & 11.4 & 41 & 4.7 & 89 & 10.3 & 867 & 52.6 \\
\hline \multicolumn{11}{|l|}{ Age, years } \\
\hline 18-19 & 53 & 67.1 & 14 & 17.7 & 7 & 8.9 & 5 & 6.3 & 79 & 4.79 \\
\hline 20-29 & 260 & 68.8 & 58 & 15.3 & 23 & 6.1 & 37 & 9.8 & 378 & 22.9 \\
\hline 30-39 & 251 & 72.1 & 34 & 9.8 & 12 & 3.5 & 51 & 14.7 & 348 & 21.1 \\
\hline $40-49$ & 219 & 73.0 & 19 & 6.3 & 8 & 2.7 & 54 & 18.0 & 300 & 18.2 \\
\hline $50+$ & 397 & 72.8 & 46 & 8.4 & 26 & 4.8 & 76 & 13.9 & 545 & 33.0 \\
\hline \multicolumn{11}{|l|}{ Educational level } \\
\hline None & 14 & 66.7 & 1 & 4.0 & 0 & 0 & 6 & 28.6 & 21 & 1.3 \\
\hline Up to high school & 753 & 69.9 & 112 & 10.4 & 52 & 4.8 & 161 & 14.9 & 1078 & 65.3 \\
\hline Some college & 257 & 74.5 & 45 & 13.0 & 18 & 5.2 & 25 & 7.3 & 345 & 20.9 \\
\hline University/postgraduate degree & 156 & 75.7 & 13 & 6.3 & 6 & 2.9 & 31 & 15.1 & 206 & 12.5 \\
\hline \multicolumn{11}{|l|}{ Diabetes } \\
\hline Yes & 82 & 67.2 & 9 & 7.4 & 9 & 7.4 & 22 & 18.0 & 122 & 7.4 \\
\hline No & 1098 & 71.9 & 162 & 10.6 & 67 & 4.4 & 201 & 13.2 & 1528 & 92.6 \\
\hline Total & 1180 & 71.2 & 171 & 10.4 & 76 & 4.6 & 223 & 13.5 & 1650 & 100 \\
\hline
\end{tabular}

more often at $\geq 30 \%$ of observed sites in moderate and heavy smokers than in both non-smokers and light smokers.

The multivariate logistic regression model (Table 3 ) points to age $\geq 50$ years as a possible risk indicator for gingival inflammation (severe gingival inflammation, GI $>2$ ), with participants in this age band being almost twice as likely to present with severe gingival inflammation as 18-19 year-old patients. Notably, participants with $\geq 30 \%$ of surfaces displaying visible plaque were dramatically more likely to have severe gingival inflammation than those with lesser VPIs. Study participants who had completed a higher education degree were less likely to have severe gingival inflammation. With respect to smoking status, light smokers were found to be at increased risk of gingival inflammation, whereas heavy smokers were at decreased like of having clinically detectable gingival inflammation. It should also be noted that (diabetes) was found to be a risk indicator of severe gingival inflammation.

Correlations between VPI and GI values, by smoking status group, are shown in Figure. For non-smokers, we obtained a correlation coefficient of 0.74 ( $p<0.001)$ whereas for smokers as a whole, we obtained $0.65(p<0.001)$. Correlation analyses of each smoker status group yielded correlation coefficients of 0.55 ( $\mathrm{p}<0.001), 0.63$ ( $\mathrm{p}<0.001)$, and 0.75 ( $\mathrm{p}<0.001)$ for light, moderate and heavy smokers, respectively.

\section{Discussion}

The present study conducted on a multi-stage probability sample of adults from Santiago, Tucumán, and Porto Alegre achieved representativeness, as demonstrated by age and gender distributions. Representative studies are important for descriptive purposes and to enhance the quality of analytical approaches. ${ }^{21}$ With respect to our study aim of examining the impact of smoking on detection of gingival disease, we observed that a high prevalence ( $>90 \%$ ) of gingival inflammation (GI > 0.5) in these three cities. ${ }^{20}$ Our multivariate model findings are in line with previous studies showing that older age, lower levels of education, higher levels of plaque, and diabetes are associated with greater gingival inflammation. 
Table 2. Distribution of clinical variables according to smoking exposure group.

\begin{tabular}{|c|c|c|c|c|c|c|c|c|c|c|c|c|c|c|c|}
\hline \multirow{2}{*}{ Variable } & \multicolumn{3}{|c|}{ Non-smoker } & \multicolumn{3}{|c|}{ Light smoker } & \multicolumn{3}{|c|}{ Moderate smoker } & \multicolumn{3}{|c|}{ Heavy smoker } & \multicolumn{3}{|c|}{ Total } \\
\hline & $\mathrm{N}$ & $\%$ cat & $\%$ tot & $\mathrm{N}$ & $\%$ cat & $\%$ tot & $N$ & $\%$ cat & $\%$ tot & $\mathrm{N}$ & $\%$ cat & $\%$ tot & $\mathrm{N}$ & $\%$ cat & $\%$ tot \\
\hline \multicolumn{16}{|l|}{$\mathrm{GI}$} \\
\hline $\mathrm{Gl}<0.5$ & 60 & 82.2 & 5.1 & 3 & 4.1 & 1.8 & 2 & 2.7 & 2.6 & 8 & 11 & 3.6 & 73 & 100 & 4.4 \\
\hline Gl 0.5-1 & 319 & 73.3 & 27.0 & 26 & 6.0 & 15.2 & 13 & 3.0 & 17.1 & 77 & 17.7 & 34.5 & 435 & 100 & 26.4 \\
\hline GI 1.1-2 & 769 & 70.4 & 65.2 & 135 & 12.4 & 78.9 & 58 & 5.3 & 76.3 & 130 & 11.9 & 58.3 & 1092 & 100 & 66.2 \\
\hline $\mathrm{Gl}<2$ & 32 & 64.0 & 2.7 & 7 & 14.0 & 4.1 & 3 & 6.0 & 3.9 & 8 & 16.0 & 3.6 & 50 & 100 & 3.1 \\
\hline Mean GI $( \pm S D)$ & \multicolumn{3}{|c|}{$1.26 \pm 0.47^{d}$} & \multicolumn{3}{|c|}{$1.45 \pm .043^{\text {ad }}$} & \multicolumn{3}{|c|}{$1.38 \pm 0.46^{\mathrm{ad}}$} & \multicolumn{3}{|c|}{$1.23 \pm 0.46^{\text {bcd }}$} & \multicolumn{3}{|c|}{$1.29 \pm 0.47$} \\
\hline Mean GI, prox $( \pm S D)$ & \multicolumn{3}{|c|}{$1.28 \pm 0.47$} & \multicolumn{3}{|c|}{$1.46 \pm 0.44$} & \multicolumn{3}{|c|}{$1.4 \pm 0.44$} & \multicolumn{3}{|c|}{$1.26 \pm 0.46$} & \multicolumn{3}{|c|}{$1.30 \pm 0.47$} \\
\hline \multicolumn{16}{|l|}{ GBI } \\
\hline $\mathrm{GBI}=0$ & 35 & 71.4 & 3.0 & 5 & 10.2 & 2.9 & 2 & 4.1 & 2.6 & 7 & 14.3 & 3.2 & 49 & 100 & 3.0 \\
\hline $\mathrm{GBI}>0$ and $<10 \%$ & 223 & 71.9 & 18.9 & 18 & 5.8 & 10.5 & 11 & 3.6 & 14.5 & 58 & 18.7 & 26.0 & 310 & 100 & 18.8 \\
\hline GBI $10.1-49.9 \%$ & 537 & 73.2 & 45.5 & 65 & 8.9 & 38.0 & 31 & 4.2 & 40.8 & 101 & 13.8 & 45.3 & 734 & 100 & 44.5 \\
\hline $\mathrm{GBI} \geq 50 \%$ & 385 & 69.1 & 32.6 & 83 & 14.9 & 48.5 & 32 & 5.8 & 42.1 & 57 & 10.2 & 25.6 & 557 & 100 & 33.8 \\
\hline Mean GBI $( \pm S D)$ & \multicolumn{3}{|c|}{$37.9 \pm 31.4$} & \multicolumn{3}{|c|}{$49.4 \pm 33.7^{a}$} & \multicolumn{3}{|c|}{$45.2 \pm 34.8$} & \multicolumn{3}{|c|}{$33.9 \pm 32.1^{\mathrm{b}}$} & \multicolumn{3}{|c|}{$38.9 \pm 32.2$} \\
\hline \multicolumn{16}{|l|}{ VPI } \\
\hline$<30 \%$ & 52 & 89.7 & 4.4 & 3 & 5.2 & 1.8 & 0 & 0 & 0 & 3 & 5.2 & 1.4 & 58 & 100 & 3.5 \\
\hline$\geq 30 \%$ & 1128 & 70.9 & 95.6 & 168 & 10.6 & 98.2 & 76 & 4.8 & 100 & 223 & 13.5 & 98.6 & 1592 & 100 & 96.5 \\
\hline Mean \pm SE $(95 \% \mathrm{Cl})$ & \multicolumn{3}{|c|}{$\begin{array}{c}0.71 \pm 0.006 \\
(0.7-0.72)\end{array}$} & \multicolumn{3}{|c|}{$\begin{array}{c}0.8 \pm 0.14 \\
(0.77-0.82)^{a}\end{array}$} & \multicolumn{3}{|c|}{$\begin{array}{c}0.8 \pm 0.14 \\
(0.77-0.84)^{a}\end{array}$} & \multicolumn{3}{|c|}{$\begin{array}{l}0.77 \pm 0.13 \\
(0.75-0.80)^{a}\end{array}$} & \multicolumn{3}{|c|}{$\begin{array}{r}0.73 \pm 0.21 \\
(0.72-0.74)\end{array}$} \\
\hline Mean prox \pm SE $(95 \% \mathrm{Cl})$ & & $\begin{array}{l}7 \pm 0 . \\
76-0.7\end{array}$ & & & $\begin{array}{l}.85 \pm 0 \\
0.82-0.8\end{array}$ & & & $\begin{array}{l}.86 \pm \\
0.83-0 .\end{array}$ & & & $\begin{array}{l}.83 \pm 0 \\
.80-0.8\end{array}$ & $\begin{array}{r}.19 \\
85)^{a}\end{array}$ & & $\begin{array}{l}9 \pm 0.2 \\
78-0.8\end{array}$ & \\
\hline Calculus & & & & & & & & & & & & & & & \\
\hline$<30 \%$ sites & 139 & 83.2 & 11.8 & 14 & 8.4 & 8.2 & 3 & 1.8 & 3.9 & 11 & 6.6 & 4.9 & 167 & 100 & 10.1 \\
\hline$\geq 30 \%$ sites & 1040 & 70.2 & 88.2 & 157 & 10.6 & 91.8 & 73 & 4.9 & 96.1 & 212 & 14.3 & 95.1 & 1482 & 100 & 89.9 \\
\hline Mean \pm SE $(95 \% \mathrm{Cl})$ & & $\begin{array}{l}7 \pm 0 . \\
75-0.7\end{array}$ & & & $\begin{array}{l}.79 \pm 0 \\
0.74-0 .\end{array}$ & & & $\begin{array}{l}.89 \pm \\
.84-0\end{array}$ & & & $\begin{array}{l}88 \pm 0 \\
.85-0.9\end{array}$ & $\begin{array}{l}.15 \\
91)^{\mathrm{ab}}\end{array}$ & & $\begin{array}{l}9 \pm 0.2 \\
78-0.8\end{array}$ & \\
\hline
\end{tabular}

${ }^{a} p<0.05$ vs. non-smokers; ${ }^{b} p<0.05$ vs. light smokers; ${ }^{c} p<0.05$ vs. moderate smokers; $d p<0.05$ chi-squared, proportion between smoking categorical variables. Group Ns as in Table 1. Abbreviations: \% cat, percentage in category; \% tot, percentage of total study population; prox, at proximal sites.

In periodontal epidemiology, the definition of disease, as well as the use of complete versus partial recordings can impact estimates substantially. ${ }^{22}$ Here, we measured clinical outcomes (GI, GBI, and VPI) at six surface sites per tooth to avoid underestimating the prevalence of gingival inflammation. While our definition of gingival inflammation (GI > 0.5) may be considered a relatively low threshold, it has been widely used. ${ }^{20,23,24}$ In addition, we used the Ainamo and Bay ${ }^{18}$ dichotomization of the GI, the GBI, to facilitate a better clinical interpretation of the findings in that the GBI considers the presence of gingival bleeding as a clinical indication of inflammation. The rationale behind using these two measures of clinical gingival inflammation is that in epidemiological and clinical settings, these are available tools. It is not tenable to evaluate subclinical inflammatory status on a day-to-day basis. Baab et al. ${ }^{25}$ demonstrated alterations in gingival blood flow in smokers consistent with subclinical inflammation. They hypothesized, based on their own and others' results with laboratory approaches (e.g. histology) that, with an underlying inflammatory cell infiltrate, gingival inflammation can be present despite a clinically decreased GBI. This latent inflammatory status may explain the high level of periodontal destruction seen in smokers. A recent joint publication from the European Federation and the American Academy of Periodontology ${ }^{26,27}$ characterized smoking as a grade modifier of periodontitis classification with profound effects in gingival tissues. It was supposed that vasoconstriction caused by smoking, together with fibrosis, could be responsible for the masking 
Table 3. Multivariate logistic regression model of risk indicators of severe gingival inflammation $(G I>2)$ in adults.

\begin{tabular}{|c|c|c|}
\hline Variable & OR & $95 \% \mathrm{Cl}$ \\
\hline \multicolumn{3}{|l|}{ Age, years } \\
\hline $18-19$ & 1 & \\
\hline $20-29$ & 1.40 & $0.81-2.41$ \\
\hline $30-39$ & 1.14 & $0.67-1.98$ \\
\hline $40-49$ & 1.31 & $0.75-2.29$ \\
\hline $50+$ & $1.93^{*}$ & $1.13-3.31$ \\
\hline \multicolumn{3}{|l|}{ VPI } \\
\hline$<30 \%$ & 1 & \\
\hline$\geq 30 \%$ & $28.1^{\psi}$ & $10.01-78.94$ \\
\hline \multicolumn{3}{|l|}{ Educational level } \\
\hline Did not complete high school & 1 & \\
\hline Completed high school & 0.44 & $0.13-1.55$ \\
\hline Some college & 0.51 & $0.14-1.81$ \\
\hline University/postgraduate degree & $0.19^{*}$ & $0.05-0.71$ \\
\hline \multicolumn{3}{|l|}{ Smoker status } \\
\hline Non-smoker & 1 & \\
\hline Light smoker & $2.27^{\psi}$ & $1.46-3.53$ \\
\hline Moderate smoker & 1.62 & $0.90-2.94$ \\
\hline Heavy smoker & $0.67^{*}$ & $0.49-0.92$ \\
\hline \multicolumn{3}{|l|}{ Diabetic } \\
\hline No & 1 & \\
\hline Yes & $2.79 \Psi$ & $1.58-4.92$ \\
\hline
\end{tabular}

of clinical signs of inflammation (e.g. bleeding on probing), despite underlying inflammatory infiltrate in smokers.

This study further sought to associate gingival inflammation with possible risk indicators to help guide the development of preventive and therapeutic strategies. The examiners were calibrated to allow international comparisons and increase the internal validity of the study. Epidemiological studies of periodontal diseases and conditions are scarce in Latin America. Prior studies have either not assessed gingival inflammation or not emphasized it as a main outcome. ${ }^{2,3}$ Studies that have examined gingival inflammation have focused mainly on children. ${ }^{1}$ The present work was unusual for its combining of a representative sample of three South American cities, with the exact same protocol for assessing gingival inflammation in adults. The impact of smoking on estimates of gingival inflammation has not been studied in depth previously, especially in population-based surveys.

The descriptive data of the present sample point to a high prevalence of gingival inflammation in adults from South America. ${ }^{19}$ Findings from the present study underscore several important points related to the impact of smoking of oral health. Firstly, it should be emphasized that smokers tend to have poor oral hygiene, as demonstrated by the higher portion of individuals with a VPI $\geq 30 \%$, as well as a higher portion with a high calculus index. Although the presence of plaque and calculus are not indicative of disease per se, plaque levels do reflect oral hygiene at the time of examination and calculus formation reflects the cumulative presence of biofilm. We focused our calculus evaluation on the lower-arch anterior teeth because they tend to have the highest occurrence of dental calculus. Inasmuch as gingival inflammation is related to oral hygiene practices, calculus presence was included as an additional behavioral variable. Thus, our findings of signs of poorer oral hygiene in smokers compared to non-smokers, as reflected by plaque and calculus, were consistent with prior findings of suboptimal health-related behaviors in smokers. ${ }^{28,29,30}$

In the present study, older age, less education, a high VPI, and diabetes were associated with higher clinically detectable gingival inflammation. When the model was adjusted for smoking status, VPI was the only variable that remained associated. Explaining these findings is challenging. Aging has been studied in depth in periodontal epidemiology and has been demonstrated to be associated with poorer oral hygiene habits, which could account for age-related effects. ${ }^{31}$ Meanwhile, epidemiological studies have demonstrated greater gingival inflammation in diabetic individuals. ${ }^{32}$

An impact of education on periodontal health has also been well demonstrated in periodontal epidemiology studies. ${ }^{10,33,34}$ In the present study, better gingival conditions, and less smoking behavior, tended to coincide with more education. Individuals with a university degree had an almost $80 \%$ protective effect against gingival inflammation. Higher education has also been shown to be beneficial in smoking-cessation programs..$^{35}$ Therefore, education should be analyzed 

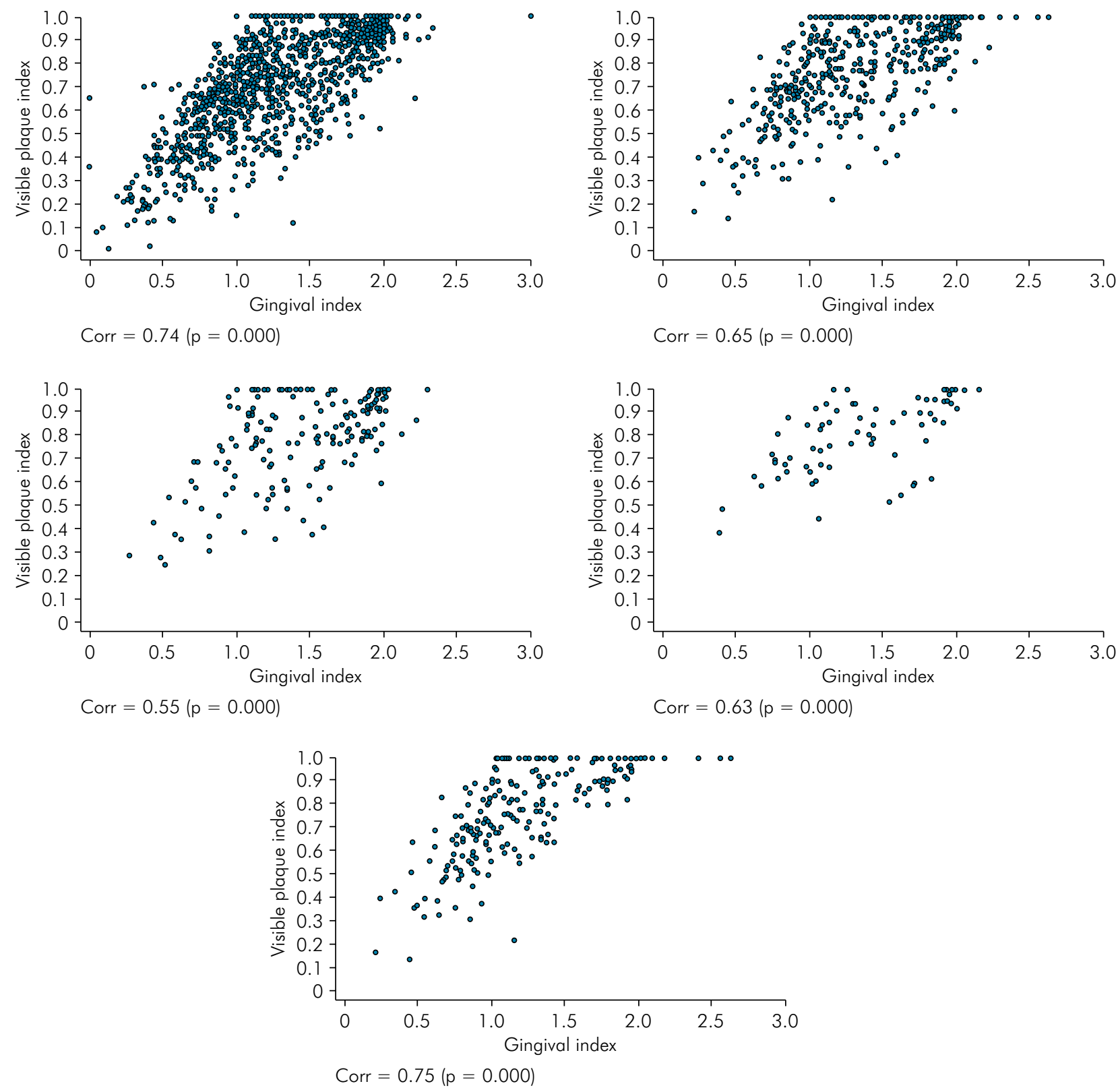

a. Non-smokers. b. All smokers. c. Light smokers. d. Moderate smokers. e. Heavy smokers.

Figure. Correlations between VPI index and GI by smoking status category.

as an important variable in the relationship between smoking and gingival inflammation.

Our finding of a positive association of VPI with gingival inflammation fits with prior studies that associated plaque with gingival inflammation. ${ }^{36} \mathrm{In}$ this respect, it is important to note that we found in the present study that when the model was controlled for smoking status, VPI was the only variable that remained associated with gingivial inflammation.
This persistence is probably due to the strength of the influence of smoking on gingival inflammatory status.

Anecdotally, smoking has been said to affect gingival bleeding. However, that supposition was not confirmed by Muller and colleagues' studies in young subjects. ${ }^{14,15,16}$ In light of the present findings, it appears that conventional gingival examination is not suitable for detecting gingival inflammation in smokers. Even if it could be described in individual case reports, data 
from large studies with representative samples are needed. The findings of the present study demonstrate an interesting relationship pattern, wherein mean GI fluctuated in a u-shaped curve, with non-smokers and heavy smokers presenting lower GI values than light and moderate smokers. Hence, heavy smoking may decrease keratinization and/or decrease gingival blood flow ${ }^{37}$, thereby affecting clinically detectable gingival inflammation, providing support to the notion that heavy smoking masks clinical estimates of gingival inflammation.

Our findings of a correlation between VPI and GI demonstrate that the correlation between plaque and gingival inflammation is highly robust regardless of smoking status, confirming decades old observations. Although smoking cannot change a pure etiological (causal) relationship, this correlation is weaker in smokers than in non-smokers. Although our analysis of smoking exposure groups does not allow for the establishment of a clear-cut relationship, this information sheds light on the importance of diagnosing gingival inflammation in smokers, while diminishing the preconception that smokers do not present gingival bleeding.

Smoking is a very important issue in oral epidemiology. In addition to being strongly associated with oral cancer ${ }^{38,39}$, periodontal destruction is strongly affected by smoking. ${ }^{37}$ The present study showed clearly that smoking can impact gingival disease estimates. Although light smoking was associated with increased gingival inflammation, heavy smoking seemed to mask signs of gingival inflammation. This effect should be considered in clinical settings as well as in epidemiological research, to control for a possible masking effect of smoking on periodontal conditions. The present study suggests that if smoking affects gingival bleeding in a clinically relevant way, the effect is apparent in heavy smokers in particular.
The coexistence of multiple risk indicators for gingival inflammation highlights the need for a common risk approach, which would be beneficial for the detection and management of several diseases and conditions, especially in the context of encouraging smoking cessation. Education also has the potential of leading to improved oral health. Hence, dentists are part of a health team with an important role in encouraging patients to stop smoking.

The present study has strengths and limitations that should be highlighted. Among the strengths were the combination of methods, the representative South American patient population, and the study of gingival inflammation in adults. Limitations included the cross-sectional study design, the use of some selfreported variables, and non-inclusion of destructive periodontal diseasea as a variable. This work is also important for its contribution to increasing awareness of the gingival inflammation burden worldwide and in Latin America, which is in need of oral health promotion. Reducing gingival inflammation has the potential to improve quality of life.

\section{Conclusion}

Gingival inflammation occurrence differs between smokers and non-smokers, and heavy smoking appears to mask the clinical signs of gingival inflammation. Risk indicators for gingival inflammation include a low level of education, diabetes, and the presence of visible plaque. There is a highly robust correlation between plaque and gingival indices regardless of smoking status.

\section{Acknowledgments}

The present study was kindly supported by an independent research grant from Colgate Palmolive.

\section{References}

1. Botero JE, Rösing CK, Duque A, Jaramillo A, Contreras A. Periodontal disease in children and adolescents of Latin America. Periodontol 2000. 2015 Feb;67(1):34-57. https://doi.org/10.1111/prd.12072

2. Oppermann RV, Haas AN, Rösing CK, Susin C. Epidemiology of periodontal diseases in adults from Latin America. Periodontol 2000.2015 Feb;67(1):13-33. https://doi.org/10.1111/prd.12061 
3. Gjermo P, Rösing CK, Susin C, Oppermann R. Periodontal diseases in Central and South America. Periodontol 2000. 2002;29(1):70-8. https://doi.org/10.1034/j.1600-0757.2001.290104.x

4. Baelum V, López R. Periodontal disease epidemiology: learned and unlearned? Periodontol 2000. 2013 Jun;62(1):37-58. https://doi.org/10.1111/j.1600-0757.2012.00449.x

5. McAfee T, Burnette D. The impact of smoking on women's health. J Womens Health (Larchmt). 2014 Nov;23(11):881-5. https://doi.org/10.1089/jwh.2014.4983

6. Zhang H, Cai B. The impact of tobacco on lung health in China. Respirology. 2003 Mar;8(1):17-21. https://doi.org/10.1046/i.1440-1843.2003.00433.x

7. Nonnemaker J, Rostron B, Hall P, MacMonegle A, Apelberg B. Mortality and economic costs from regular cigar use in the United States, 2010. Am J Public Health. 2014 Sep;104(9):e86-91. https://doi.org/10.2105/AJPH.2014.301991

8. Fosson GH, McCallum DM, Beeson DH. The health and economic consequences of cigarette smoking in Alabama, 2009-2010. Public Health Rep. 2014 Nov-Dec;129(6):486-90. https://doi.org/10.1177/003335491412900606

9. Hauri DD, Lieb CM, Rajkumar S, Kooijman C, Sommer HL, Röösli M. Direct health costs of environmental tobacco smoke exposure and indirect health benefits due to smoking ban introduction. Eur J Public Health. 2011 Jun;21(3):316-22. https://doi.org/10.1093/eurpub/ckq142

10. Haas AN, Wagner MC, Oppermann RV, Rösing CK, Albandar JM, Susin C. Risk factors for the progression of periodontal attachment loss: a 5-year population-based study in South Brazil. J Clin Periodontol. 2014 Mar;41(3):215-23. https://doi.org/10.1111/icpe.12213

11. Bergström J, Eliasson S, Dock J. A 10-year prospective study of tobacco smoking and periodontal health. J Periodontol. 2000 Aug;71(8):1338-47. https://doi.org/10.1902/jop.2000.71.8.1338

12. Susin C, Oppermann RV, Haugejorden O, Albandar JM. Periodontal attachment loss attributable to cigarette smoking in an urban Brazilian population. J Clin Periodontol. 2004 Nov;31(11):951-8. https://doi.org/10.1111/j.1600-051x.2004.00588.x

13. Tomar SL, Asma S. Smoking-attributable periodontitis in the United States: findings from NHANES III. National Health and Nutrition Examination Survey. J Periodontol. 2000 May;71(5):743-51. https://doi.org/10.1902/jop.2000.71.5.743

14. Müller HP, Stadermann S, Heinecke A. Bleeding on probing in smokers and non-smokers in a steady state plaque environment. Clin Oral Investig. 2001 Sep;5(3):177-84. https://doi.org/10.1007/s007840100126

15. Müller HP, Stadermann S, Heinecke A. Longitudinal association between plaque and gingival bleeding in smokers and non-smokers. J Clin Periodontol. 2002 Apr;29(4):287-94. https://doi.org/10.1034/j.1600-051X.2002.290403.x

16. Müller HP, Stadermann S. Multivariate multilevel models for repeated measures in the study of smoking effects on the association between plaque and gingival bleeding. Clin Oral Investig. 2006 Dec;10(4):311-6. https://doi.org/10.1007/s00784-006-0067-y PMID:16896834

17. Löe H. The Gingival Index, the Plaque Index and the Retention Index Systems. J Periodontol. 1967 Nov-Dec;38(6 Suppl):610-6. https://doi.org/10.1902/jop.1967.38.6.610

18. Ainamo J, Bay I. The Gingival Index, the Plaque Index and the Retention Index Systems. Int Dent J. 1975;25:229-35.

19. Li Y, Lee S, Hujoel P, Su M, Zhang W, Kim J, et al. Prevalence and severity of gingivitis in American adults. Am J Dent. 2010 Feb;23(1):9-13.

20. Carvajal P, Gómez M, Gomes S, Costa R, Toledo A, Solanes F, et al. Prevalence, severity, and risk indicators of gingival inflammation in a multi-center study on South American adults: a cross sectional study. J Appl Oral Sci. 2016 Sep-Oct;24(5):524-34. https://doi.org/10.1590/1678-775720160178

21. Susin C, Oppermann RV, Haugejorden O, Albandar JM. Tooth loss and associated risk indicators in an adult urban population from south Brazil. Acta Odontol Scand. 2005 Apr;63(2):85-93. https://doi.org/10.1080/00016350510019694

22. Kingman A, Susin C, Albandar JM. Effect of partial recording protocols on severity estimates of periodontal disease. J Clin Periodontol. 2008 Aug;35(8):659-67. https://doi.org/10.1111/j.1600-051X.2008.01243.x

23. Idrees MM, Azzeghaiby SN, Hammad MM, Kujan OB. Prevalence and severity of plaque-induced gingivitis in a Saudi adult population. Saudi Med J. 2014 Nov;35(11):1373-7.

24. Zhang J, Xuan D, Fan W, Zhang X, Dibart S, De Vizio W, et al. Severity and prevalence of plaque-induced gingivitis in the Chinese population. Compend Contin Educ Dent. 2010 Oct;31(8):624-9.

25. Baab DA, Oberg PA. The effect of cigarette smoking on gingival blood flow in humans. J Clin Periodontol. 1987 Aug;14(7):418-24. https://doi.org/10.1111/j.1600-051X.1987.tb01547.x

26. Papapanou PN, Sanz M, Buduneli N, Dietrich T, Feres M, Fine DH, et al. Periodontitis: Consensus report of workgroup 2 of the 2017 World Workshop on the Classification of Periodontal and Peri-Implant Diseases and Conditions. J Clin Periodontol. 2018 Jun;45 Suppl 20:S16270. https://doi.org/10.1111/icpe.12946

27. Chapple IL, Mealey BL, Van Dyke TE, Bartold PM, Dommisch H, Eickholz P, et al. Periodontal health and gingival diseases and conditions on an intact and a reduced periodontium: Consensus report of workgroup 1 of the 2017 World Workshop on the Classification of Periodontal and Peri-Implant Diseases and Conditions. J Clin Periodontol. 2018 Jun;45 Suppl 20:S68-77. https://doi.org/10.1111/icpe.12940

28. Tubaishat RS, Malkawi ZA, Albashaireh ZS. The influence of different factors on the oral health status of smoking and nonsmoking adults. J Contemp Dent Pract. 2013 Jul;14(4):731-7. https://doi.org/10.5005/ip-journals-10024-1392 
Impact of smoking on gingival inflammation in representative samples of three South American cities

29. Bergström J, Cederlund K, Dahlén B, Lantz AS, Skedinger M, Palmberg L, et al. Dental health in smokers with and without COPD. PLoS One. 2013;8(3):e59492. https://doi.org/10.1371/journal.pone.0059492

30. Mesquita R, Gonçalves CG, Hayashi D, Costa VS, Teixeira DC, Freitas ER, et al. Smoking status and its relationship with exercise capacity, physical activity in daily life and quality of life in physically independent, elderly individuals. Physiotherapy. 2015 Mar;101(1):55-61. https://doi.org/10.1016/i.physio.2014.04.008

31. Bidinotto AB, Martins AB, Dos Santos CM, Hugo FN, Hilgert JB, Celeste RK, et al. Four-year incidence rate and predictors of root caries among community-dwelling south Brazilian older adults. Community Dent Oral Epidemiol. 2018 Apr;46(2):125-31. https://doi.org/10.1111/cdoe.12343

32. Hong M, Kim HY, Seok H, Yeo CD, Kim YS, Song JY, et al. Prevalence and risk factors of periodontitis among adults with or without diabetes mellitus. Korean J Intern Med (Korean Assoc Intern Med). 2016 Sep;31(5):910-9. https://doi.org/10.3904/kjim.2016.031

33. Susin C, Haas AN, Opermann RV, Albandar JM. Tooth loss in a young population from south Brazil. J Public Health Dent. 2006;66(2):1 10-5. https://doi.org/10.1111/j.1752-7325.2006.tb02565.x

34. Wu YM, Ren F, Chen LL, Sun WL, Liu J, Lei LH, et al. Possible socioeconomic and oral hygiene behavioural risk factors for selfreported periodontal diseases in women of childbearing age in a Chinese population. Oral Health Prev Dent. 2014;12(2):171-81. https://doi.org/10.3290/i.ohpd.a31671

35. Zhuang YL, Gamst AC, Cummins SE, Wolfson T, Zhu SH. Comparison of smoking cessation between education groups: findings from 2 US National Surveys over 2 decades. Am J Public Health. 2015 Feb;105(2):373-9. https://doi.org/10.2105/AJPH.2014.302222

36. David SC, Mário TG, Freitas GC, Kantorski KZ, Wikesiö UM, Moreira CH. Correlation between plaque control and gingival health using short and extended oral hygiene intervals. Clin Oral Investig. 2018 Sep;22(7):2593-7. https://doi.org/10.1007/s00784-018-2358-5

37. Johannsen A, Susin C, Gustafsson A. Smoking and inflammation: evidence for a synergistic role in chronic disease. Periodontol 2000.2014 Feb;64(1):111-26. https://doi.org/10.1111/j.1600-0757.2012.00456.x

38. Lubin JH, Gaudet MM, Olshan AF, Kelsey K, Boffetta P, Brennan P, et al. Body mass index, cigarette smoking, and alcohol consumption and cancers of the oral cavity, pharynx, and larynx: modeling odds ratios in pooled case-control data. Am J Epidemiol. 2010 Jun;171(12):1250-61. https://doi.org/10.1093/aje/kwq088

39. Warnakulasuriya S. Global epidemiology of oral and oropharyngeal cancer. Oral Oncol. 2009 Apr-May;45(4-5):309-16. https://doi.org/10.1016/i.oraloncology.2008.06.002 